\title{
BMJ Open Non-cancer morbidity among Estonian Chernobyl cleanup workers: a register-based cohort study
}

\author{
Kaja Rahu, ${ }^{1}$ Evelyn J Bromet, ${ }^{2}$ Timo Hakulinen, ${ }^{3}$ Anssi Auvinen, ${ }^{4,5}$ \\ Anneli Uusküla, ${ }^{6}$ Mati Rahu $^{1}$
}

To cite: Rahu K, Bromet EJ, Hakulinen $\mathrm{T}$, et al. Noncancer morbidity among Estonian Chernobyl cleanup workers:

a register-based cohort study. BMJ Open 2014;4:e004516. doi:10.1136/bmjopen-2013004516

- Prepublication history for this paper is available online. To view these files please visit the journal online (http://dx.doi.org/10.1136/ bmjopen-2013-004516).

Received 20 November 2013 Revised 17 April 2014 Accepted 23 April 2014

\section{CrossMark}

${ }^{1}$ Department of Epidemiology and Biostatistics, National Institute for Health Development, Tallinn, Estonia ${ }^{2}$ Department of Psychiatry and Behavioral Science, Stony Brook University School of Medicine, Stony Brook, New York, USA

${ }^{3}$ Finnish Cancer Registry, Helsinki, Finland

${ }^{4}$ School of Health Sciences, University of Tampere, Tampere, Finland

${ }^{5}$ Radiation and Nuclear Safety Authority, Helsinki, Finland ${ }^{6}$ Department of Public Health, University of Tartu, Tartu, Estonia

Correspondence to Dr Kaja Rahu; kaja.rahu@tai.ee

\section{ABSTRACT}

Objective: To examine non-cancer morbidity in the Estonian Chernobyl cleanup workers cohort compared with the population sample with special attention to radiation-related diseases and mental health disorders.

Design: Register-based cohort study.

Setting: Estonia.

Participants: An exposed cohort of 3680 men (cleanup workers) and an unexposed cohort of 7631 men (population sample) were followed from 2004 to 2012 through the Population Registry and Health Insurance Fund database.

Methods: Morbidity in the exposed cohort compared with the unexposed controls was estimated in terms of rate ratio (RR) with $95 \%$ Cls using Poisson regression models.

Results: Elevated morbidity in the exposed cohort was found for diseases of the nervous system, digestive system, musculoskeletal system, ischaemic heart disease and for external causes. The most salient excess risk was observed for thyroid diseases (RR $=1.69 ; 95 \% \mathrm{Cl} 1.38$ to 2.07), intentional self-harm ( $R R=1.47 ; 95 \% \mathrm{Cl} 1.04$ to 2.09) and selected alcohol-related diagnoses ( $R R=1.25$; $95 \% \mathrm{Cl} 1.12$ to 1.39 ). No increase in morbidity for stress reactions, depression, headaches or sleep disorders was detected.

Conclusions: No obvious excess morbidity consistent with biological effects of radiation was seen in the exposed cohort, with the possible exception of benign thyroid diseases. Increased alcohol-induced morbidity may reflect alcohol abuse, and could underlie some of the higher morbidity rates. Mental disorders in the exposed cohort were probably under-reported. The future challenge will be to study mental and physical comorbidities in the Chernobyl cleanup workers cohort.

\section{INTRODUCTION}

In the aftermath of the accident at the Chernobyl nuclear power station in April 1986, about 530000 men from throughout the former Soviet Union were commissioned to the area to clean up the environment. ${ }^{1}$ Among them were nearly 5000 (mostly)

\section{Strengths and limitations of this study}

- Morbidity information provided in this study was obtained from population-based registries via electronic record linkages using personal identification number as the key variable.

- The follow-up of cohort members was complete.

- Limitations of the study are as follows: relatively short follow-up; the probable presence of tentative and preliminary diagnoses in the health insurance database; questionable accuracy and precision of officially documented doses.

military reservists from Estonia who worked in the contaminated area for 3 months on average; their mean received cumulative whole-body radiation dose was $0.1 \mathrm{~Gy}^{2}$

Epidemiological evidence of non-cancer disease risk in the cohorts exposed to ionising radiation is mainly based on mortality since administratively registered death records are available and easy to use for linkages. Most of these studies have focused on circulatory diseases, the major cause of death in developed countries. Excess mortality from all circulatory diseases, stroke and heart disease was observed in atomic-bomb survivors; however, the association below a dose of 0.5 Gy was not significant. ${ }^{3}$ Follow-up of nuclear industry workers from 15 countries resulted in no significant findings for a dose-dependent rise in mortality from circulatory diseases. ${ }^{4}$ Elevated risk of death for the broad categories of diseases of the respiratory and digestive systems has been found among atomic-bomb survivors, ${ }^{5}$ but not in other environmentally exposed populations ${ }^{6}$ or in nuclear industry workers. ${ }^{4}$

A few studies have reported morbidity outcomes. The most informative non-cancer disease incidence study of atomic-bomb survivors found significant radiation effects for thyroid diseases, liver diseases, cataract and calculus of the kidney and ureter. ${ }^{7}$ The morbidity study of Mayak nuclear weapons facility 
workers demonstrated an increasing dose-related trend for cerebrovascular diseases ${ }^{8}$ and ischaemic heart disease, ${ }^{9}$ but did not provide information on risk at doses below $0.2 \mathrm{~Gy}$. A meta-analysis by Little et $a l^{10} \mathrm{com}$ bining morbidity and mortality studies of occupationally and environmentally exposed populations with mean dose below $0.5 \mathrm{~Gy}$ demonstrated significantly increased dose-dependent risk for ischaemic heart disease, cerebrovascular diseases and other circulatory diseases.

Analyses of non-cancer morbidity in a cohort of Russian Chernobyl cleanup workers have shown dose-dependent excess (per 1 Gy) for endocrine and metabolic diseases, mental disorders, diseases of the nervous system, diseases of the digestive system, cerebrovascular diseases, hypertension and ischaemic heart disease. ${ }^{11}{ }^{12}$ However, risk estimates at low doses still remain uncertain. ${ }^{13}$

Although the psychological aftermath of the Chernobyl accident has been acknowledged as the major long-term public health problem in the exposed populations, ${ }^{1}{ }^{14}$ the mental health of cleanup workers has only been assessed in small-scale studies in Ukraine. ${ }^{15}{ }^{16}$ There is an urgent need to examine mental health along with somatic diseases when considering the health of cleanup workers. ${ }^{16}$

An updated analysis of mortality and cancer incidence in the Estonian Chernobyl cohort revealed higher incidence of alcohol-related cancers and excess of suicide. ${ }^{2}$ Suicide risk has been persistently elevated since the beginning of follow-up. ${ }^{17} 18$ The current research provides the first overview of morbidity other than cancer in the Estonian cohort of Chernobyl cleanup workers with special attention to radiation-related diseases and mental health disorders.

\section{METHODS}

\section{Sample and follow-up}

The Estonian cohort of Chernobyl cleanup workers (exposed cohort) includes 4831 men recruited between 1986 and 1991 to the Chernobyl area by the Soviet authorities for decontamination, building and other related activities. The 'Chernobyl area' here denotes the $30 \mathrm{~km}$ zone (an area of $30 \mathrm{~km}$ radius from the nuclear power station) and territories outside, where the workers were engaged with different activities during their mission period. Detailed information on the assembly and description of the cohort is given elsewhere. ${ }^{19}$ To examine morbidity in this cohort, we used data from the Estonian Health Insurance Fund (EHIF) database available since January 2004. Thus, for the morbidity analyses we identified all cohort members aged 35-69 years and living in Estonia on 1 January 2004. Altogether, of the 4831 men in the initial cohort, 1129 were excluded because of loss to follow-up (21), death (602) and emigration (506). In addition, we did not include men aged under 35 (9) and over 69 years (13) to have a more homogeneous age group. This left just 3680 cleanup workers in the study. An unexposed population-based comparison cohort was selected corresponding to the age distribution of the exposed cohort. A random sample stratified by 5-year age groups with the exposed to unexposed ratio of 1:2 and 5\% extra men in each age group was extracted from the Estonian Population Registry (EPR). In the unexposed cohort, after excluding 87 men who had worked in the Chernobyl area (cleanup workers), there remained 7631 men.

The cohort of cleanup workers was linked to the EPR to update vital status (emigration or death with corresponding date), ethnicity and education. Each person in both cohorts was followed up from 1 January 2004 until death, emigration or 31 December 2012 (whichever date came first). From the EHIF database, we obtained dates and international classification of diseases (ICD-10) codes for each contact with a health provider. All linkages were performed using the unique personal identification number (assigned to all permanent residents of Estonia) as the key variable. EHIF manages the mandatory universal health insurance system that is based on solidarity and covers $95 \%$ of the Estonian population. ${ }^{20}$ All employees and self-employed persons contribute $13 \%$ of their wages; some groups of the population are financed by the State (eg, registered unemployed, Chernobyl veterans) and some groups are insured without contribution (eg, children, students, pensioners). People without coverage from the aforementioned sources can pay tax voluntarily.

Healthcare contacts were identified from the EHIF database for 2004-2012 using the first occurrence of the three-digit ICD-10 code. If the contact involved multiple diagnoses, the first occurrence of each of them was separately counted. All diseases (except cancer, ICD-10 C00-C97), external causes of morbidity and examinations or counselling were considered. Four-digit codes were taken separately only for some alcohol-induced diseases. A combined category of alcohol-induced diagnoses included mental disorders due to alcohol (F10), degeneration of the nervous system due to alcohol (G31.2), alcoholic cardiomyopathy (I42.6), alcoholic liver disease (K70), alcohol-induced pancreatitis (K86.0), accidental poisoning by alcohol (X45), intentional self-poisoning by alcohol (X65) and poisoning by alcohol, undetermined intent (Y15). The accuracy of diagnosis was the responsibility of the physician issuing the invoice to EHIF for ambulatory or hospital care.

\section{Morbidity measures and statistical analysis}

We estimated morbidity in the cleanup workers cohort by means of rate ratio (RR) with 95\% CIs using Poisson regression models with the logarithm of the person-years at risk (summed by 5-year age groups) as the offset. ${ }^{21} \mathrm{At}$ first, we performed an analysis comparing the exposed cohort with the unexposed cohort (external analysis) to obtain an overview of morbidity RRs. Diagnoses were grouped into broad categories with selected specific diagnoses. Analyses were adjusted for age at diagnosis by 5-year age groups. 
Additionally, analysis was carried out on different subgroups within the exposed cohort (internal analysis) to assess possible effects of year of arrival in the Chernobyl area (1986; 1987-1991), duration of stay $(<92 ; \geq 92$ days $)$ and documented cumulative whole-body radiation dose $(<5.0 ; 5.0-9.9 ; \geq 10.0 \mathrm{cGy})$ on morbidity risk. As described elsewhere, ${ }^{1}{ }^{22} 23$ the cleanup workers were dominantly exposed to $\gamma$-radiation released mainly by ${ }^{131} \mathrm{I},{ }^{134} \mathrm{Cs}$ and ${ }^{137} \mathrm{Cs}$. Received radiation doses were measured by individual or group dosimeters, or estimated by work area measurements. The readings were documented in the workers' military passports/records. Considering that documented doses were unreliable, ${ }^{19}$ and not recorded for $15.2 \%$ of the cohort members, we used year of arrival and duration of stay as proxy variables for radiation exposure.

Potential confounders-educational level (higher or secondary; basic or less) and ethnicity (Estonian; non-Estonian (mainly Russians)) - were included in the analysis as surrogates for health behaviour. The prevalence of alcohol consumption at least once a week $(28.5 \%)$ and current smoking (69\%) among the cleanup workers was studied in a postal questionnaire survey conducted in $1992-1993,{ }^{19}$ but not included in current analyses due to small cohort size and lack of longitudinal data on these factors of health behaviour. Thus, the selection of variables (potential confounders) was determined by their availability and a review of our previous studies.

Analyses within the exposed cohort focused on disease risks previously reported in atomic-bomb survivors and Chernobyl cleanup workers. ${ }^{711} 12$ The first set of models included the year of arrival in the Chernobyl area, duration of stay, age at diagnosis, education and ethnicity. One hundred and seventy-four participants with missing information for any characteristic were excluded from the analysis. In the second set of models we included documented radiation dose; due to unrecorded values, an additional 452 participants were excluded.

We used Visual FoxPro 6.0 (Microsoft Corporation, Redmond, Washington, USA) for database management, and Stata 12 (StataCorp LP, College Station, Texas, USA) for statistical modelling.

\section{RESULTS}

Description of the exposed and unexposed cohorts

We followed 3680 exposed and 7631 unexposed men from 1 January 2004 to 31 December 2012 (table 1). The exposed and unexposed cohorts contributed 30674 and 65112 person-years, respectively. Mean age at the start of follow-up was 48 years in both cohorts. During the follow-up, $12.9 \%$ of the exposed cohort and $10.5 \%$ of the unexposed cohort died. The proportions of non-Estonians (mainly Russians) and less educated persons were higher in the exposed cohort, although educational level was unknown for $16.4 \%$ of the participants in the unexposed cohort. Two-thirds of the cleanup workers entered the Chernobyl area in 1986; the mean and median durations of the mission were 102 and 92 days, respectively (range: 1-833 days). The cohort was exposed to low-level whole-body radiation with the mean and median documented radiation doses of 9.9 and $8.9 \mathrm{cGy}$, respectively (range: $0.0-54.5 \mathrm{cGy}$ ).

Nearly all men had at least one record in the EHIF database $(93.6 \%$ of the exposed and $95.3 \%$ of the unexposed cohort). On average, members of both cohorts had 12 different diagnoses (3-digit ICD-10 codes). Men in the exposed cohort had their first health services contact on average half a year earlier than their unexposed counterparts (52.1 vs 52.6 years of age).

\section{Morbidity in the exposed cohort in relation to the unexposed cohort (external analysis)}

In the external analysis (table 2), we observed a very small increase of borderline significance in all-disease risk among Chernobyl cleanup workers $(\mathrm{RR}=1.01 ; 95 \%$ CI 1.00 to 1.03). From the non-cancer late effects that might be related to the Chernobyl accident (UNSCEAR 2011), we found significantly elevated morbidity for diseases of the thyroid gland ( $\mathrm{RR}=1.69 ; 95 \%$ CI 1.38 to $2.07)$ and ischaemic heart disease ( $R R=1.09 ; 95 \%$ CI 1.00 to 1.18). There was evidence of lower occurrence of cataract in the exposed cohort. Stress reactions, depression, severe headaches and sleep disorders were not diagnosed more frequently in the exposed cohort than in the reference cohort.

Increased morbidity was apparent for the broad categories of diseases of the nervous system, digestive system, musculoskeletal system and alcohol-induced diagnoses. Morbidity from external causes in the exposed cohort exceeded that in the unexposed cohort $(\mathrm{RR}=1.07 ; 95 \%$ CI 1.03 to 1.11 ). Significantly higher morbidity was registered for falls, intentional self-harm and exposure to excessive cold. Cleanup workers did not undergo medical observations for suspected diseases (ICD-10 Z03) more frequently than unexposed men $(\mathrm{RR}=1.06 ; 95 \% \mathrm{CI}$ 0.94 to 1.19 ). Additional adjustments for ethnicity and education (RRs not presented) did not materially alter these results.

\section{Differences between subgroups in the exposed cohort (internal analysis)}

Internal analysis revealed more depressive disorders and stress reactions ( $\mathrm{RR}=1.27 ; 95 \% \mathrm{CI} 1.00$ to 1.62$)$ and severe headaches ( $R R=1.69 ; 95 \%$ CI 1.10 to 2.60$)$ among cleanup workers who entered the area shortly after the accident than in those arriving later (table 3). Higher thyroid disease morbidity was not related to year or month (April-May vs June-December, 1986) of arrival in the contaminated area. Longer mission did not increase the morbidity of any disease. Acute myocardial infarction, cerebrovascular diseases, diseases of liver, calculus of kidney and ureter, headaches and alcohol-induced morbidity occurred more frequently among non-Estonians, while mental disorders were more frequent among 
Table 1 Characteristics of the Estonian cohort of Chernobyl cleanup workers (exposed cohort) and the unexposed comparison cohort

\begin{tabular}{|c|c|c|c|c|}
\hline \multirow[b]{2}{*}{ Characteristic } & \multicolumn{2}{|c|}{ Exposed cohort } & \multicolumn{2}{|c|}{ Unexposed cohort } \\
\hline & $\mathbf{N}$ & $(\%)$ & $\mathbf{N}$ & (\%) \\
\hline Total & 3680 & 100 & 7631 & 100 \\
\hline \multicolumn{5}{|c|}{ Vital status on 31 December 2012} \\
\hline Living in Estonia & 3132 & 85.1 & 6795 & 89.0 \\
\hline Dead & 474 & 12.9 & 798 & 10.5 \\
\hline Emigrated & 74 & 2.0 & 38 & 0.5 \\
\hline \multicolumn{5}{|c|}{ Age at start of follow-up (full years } \\
\hline $35-44$ & 1265 & 34.4 & 2645 & 34.7 \\
\hline $45-54$ & 1850 & 50.3 & 3738 & 49.0 \\
\hline $55-64$ & 536 & 14.6 & 1186 & 15.5 \\
\hline$\geq 65$ & 29 & 0.8 & 62 & 0.8 \\
\hline \multicolumn{5}{|c|}{ Person-years in an age group (2004-2012 } \\
\hline $35-44$ & 4718.4 & 15.4 & 9416.1 & 14.5 \\
\hline $45-54$ & $15,513.5$ & 50.6 & 32825.3 & 50.4 \\
\hline $55-64$ & 9303.9 & 30.3 & 20126.9 & 30.9 \\
\hline$\geq 65$ & 1138.6 & 3.7 & 2743.5 & 4.2 \\
\hline Total & 30674.4 & 100 & 65111.8 & 100 \\
\hline \multicolumn{5}{|l|}{ Ethnicity } \\
\hline Estonian & 2036 & 55.3 & 4690 & 61.5 \\
\hline Non-Estonian & 1643 & 44.6 & 2848 & 37.3 \\
\hline Unknown & 1 & 0.0 & 93 & 1.2 \\
\hline \multicolumn{5}{|l|}{ Education } \\
\hline Higher & 322 & 8.8 & 1159 & 15.2 \\
\hline Secondary & 2446 & 66.5 & 4017 & 52.6 \\
\hline Basic or less & 824 & 22.4 & 1200 & 15.7 \\
\hline Unknown & 88 & 2.4 & 1255 & 16.4 \\
\hline \multicolumn{5}{|c|}{ Time of arrival in the Chernobyl area } \\
\hline 1986, April-May & 1154 & 31.4 & & \\
\hline 1986, June-December & 1128 & 30.7 & & \\
\hline 1986 , month unknown & 13 & 0.4 & & \\
\hline 1987 & 820 & 22.3 & & \\
\hline 1988 & 417 & 11.3 & & \\
\hline 1989-1991 & 67 & 1.8 & & \\
\hline Unknown & 81 & 2.2 & & \\
\hline \multicolumn{5}{|c|}{ Duration of stay in the Chernobyl area (days } \\
\hline$<30$ & 220 & 6.0 & & \\
\hline $30-89$ & 1487 & 40.4 & & \\
\hline $90-149$ & 1163 & 31.6 & & \\
\hline 150-209 & 648 & 17.6 & & \\
\hline$\geq 210$ & 60 & 1.6 & & \\
\hline Ūnknown & 102 & 2.8 & & \\
\hline \multicolumn{5}{|l|}{ Documented dose (cGy } \\
\hline$<5.0$ & 810 & 22.0 & & \\
\hline $5.0-9.9$ & 1022 & 27.8 & & \\
\hline $10.0-14.9$ & 555 & 15.1 & & \\
\hline $15.0-19.9$ & 519 & 14.1 & & \\
\hline $20.0-24.9$ & 195 & 5.3 & & \\
\hline$\geq 25.0$ & 21 & 0.6 & & \\
\hline Unknown & 558 & 15.2 & & \\
\hline
\end{tabular}

Estonians. Less educated cleanup workers had higher risk for diseases of the nervous system, cerebrovascular diseases, intentional self-harm and alcohol-induced morbidity, and lower risk for in situ and benign neoplasms.

Including education and ethnicity in the model did not alter markedly the crude point estimates of RR for year of arrival or duration of stay (RRs not presented). Higher documented radiation dose $(5.0-9.9$ or $\geq 10.0$ vs $<5.0 \mathrm{cGy}$ ) was not associated with higher morbidity of thyroid diseases $(\mathrm{RR}=0.92 ; 95 \% \mathrm{CI} 0.60$ to $1.40 ; 0.92$; 0.60 to 1.40 , respectively), cataract ( $R R=1.26 ; 95 \%$ CI 0.80 to $1.98 ; 1.13 ; 0.70$ to 1.83 , respectively) or any of the other selected diseases. 
Table 2 Number of morbidity cases* and age-adjusted morbidity RR $\uparrow$ with $95 \% \mathrm{Cls}$ in the Estonian cohort of Chernobyl cleanup workers (exposed cohort) in relation to the unexposed comparison cohort, 2004-2012

\begin{tabular}{|c|c|c|c|c|}
\hline \multirow[b]{2}{*}{ ICD-10 } & \multirow[b]{2}{*}{ Diagnosis/external cause of morbidity } & \multicolumn{2}{|c|}{ No. of cases } & \multirow[b]{2}{*}{$\operatorname{RR}(95 \% \mathrm{Cl})$} \\
\hline & & $\begin{array}{l}\text { Exposed } \\
\text { cohort }\end{array}$ & $\begin{array}{l}\text { Unexposed } \\
\text { cohort }\end{array}$ & \\
\hline A00-R99, V01-Z99 & All diagnoses and external causes & 41370 & 86441 & $1.02(1.01$ to 1.03$) \ddagger$ \\
\hline A00-R99, except C00-C97 & All diseases, except cancer & 31757 & 66799 & $1.01(1.00$ to 1.03$)$ \\
\hline A00-B99 & Infectious diseases & 1338 & 3022 & $0.94(0.88$ to 1.00$)$ \\
\hline A15-A16 & Respiratory tuberculosis & 41 & 73 & $1.19(0.81$ to 1.74$)$ \\
\hline D00-D48 & In situ and benign neoplasms & 517 & 1060 & $1.04(0.94$ to 1.16$)$ \\
\hline D50-D89 & $\begin{array}{l}\text { Diseases of the blood and blood-forming } \\
\text { organs }\end{array}$ & 97 & 195 & $1.07(0.84$ to 1.36$)$ \\
\hline E00-E90 & $\begin{array}{l}\text { Endocrine, nutritional and metabolic } \\
\text { diseases }\end{array}$ & 806 & 1754 & $0.98(0.90$ to 1.07$)$ \\
\hline E00-E07 & Diseases of thyroid gland & 167 & 211 & 1.69 (1.38 to 2.07$) \ddagger$ \\
\hline F00-F99 & Mental disorders & 1380 & 2918 & $1.00(0.94$ to 1.07$)$ \\
\hline F10 & Mental disorders due to alcohol & 328 & 570 & $1.21(1.06$ to 1.39$) \ddagger$ \\
\hline F32-F33 & Depressive disorders & 290 & 633 & $0.97(0.84$ to 1.11$)$ \\
\hline $\mathrm{F} 41$ & Anxiety disorders & 119 & 275 & $0.91(0.74$ to 1.13$)$ \\
\hline F43 & Stress reactions & 55 & 162 & $0.72(0.53$ to 0.97$) \ddagger$ \\
\hline G00-G99 & Diseases of the nervous system & 1352 & 2550 & $1.13(1.06$ to 1.21$) \ddagger$ \\
\hline G31.2 & $\begin{array}{l}\text { Degeneration of nervous system } \\
\text { due to alcohol }\end{array}$ & 48 & 68 & $1.51(1.04$ to 2.18$) \ddagger$ \\
\hline G40 & Epilepsy & 148 & 223 & $1.40(1.14$ to 1.73$) \ddagger$ \\
\hline G43-G44 & Migraine and other headache & 125 & 256 & $1.03(0.83$ to 1.28$)$ \\
\hline G50-G59 & Nerve, nerve root and plexus disorders & 447 & 829 & $1.15(1.02$ to 1.29$) \ddagger$ \\
\hline F51, G47 & Sleep disorders & 267 & 529 & $1.08(0.93$ to 1.25$)$ \\
\hline H0O-H59 & Diseases of the eye & 2004 & 4592 & $0.93(0.89$ to 0.98$) \ddagger$ \\
\hline H25-H26, H28 & Cataract & 155 & 449 & $0.77(0.64$ to 0.92$) \ddagger$ \\
\hline $\mathrm{H} 40, \mathrm{H} 42$ & Glaucoma & 109 & 247 & $0.96(0.77$ to 1.20$)$ \\
\hline H60-H95 & Diseases of the ear & 1228 & 2707 & 0.97 (0.91 to 1.04$)$ \\
\hline $100-199$ & Diseases of the circulatory system & 4432 & 9477 & $1.00(0.97$ to 1.04$)$ \\
\hline$|10-| 15$ & Hypertensive diseases & 1936 & 4210 & $0.98(0.93$ to 1.04$)$ \\
\hline $120-125$ & Ischaemic heart disease & 773 & 1537 & 1.09 (1.00 to 1.18$)$ \\
\hline 121 & Acute myocardial infarction & 104 & 214 & 1.05 (0.83 to 1.33$)$ \\
\hline $160-169$ & Cerebrovascular diseases & 291 & 606 & $1.05(0.91$ to 1.20$)$ \\
\hline J00-J99 & Diseases of the respiratory system & 4699 & 10079 & 0.99 (0.95 to 1.02$)$ \\
\hline J30-J39 & Diseases of upper respiratory tract & 592 & 1431 & $0.87(0.79$ to 0.96$) \ddagger$ \\
\hline J40-J47 & Lower respiratory diseases & 580 & 1130 & 1.10 (1.00 to 1.22$)$ \\
\hline K00-K93 & Diseases of the digestive system & 3179 & 6068 & $1.11(1.07$ to 1.16$) \ddagger$ \\
\hline K20-K31 & $\begin{array}{l}\text { Diseases of oesophagus, stomach } \\
\text { and duodenum }\end{array}$ & 1415 & 2648 & $1.14(1.06$ to 1.21$) \ddagger$ \\
\hline K25-K27 & Peptic ulcer & 464 & 857 & $1.15(1.02$ to 1.28$) \ddagger$ \\
\hline K70-K77 & Diseases of liver & 194 & 357 & $1.16(0.97$ to 1.38$)$ \\
\hline K70 & Alcoholic liver disease & 68 & 117 & $1.23(0.91$ to 1.66$)$ \\
\hline K85-K86 & Diseases of pancreas & 128 & 213 & $1.27(1.02$ to 1.58$) \ddagger$ \\
\hline K86.0 & Alcohol-induced pancreatitis & 25 & 41 & 1.27 (0.77 to 2.09$)$ \\
\hline L00-L99 & Diseases of the skin & 1793 & 3730 & $1.02(0.97$ to 1.08$)$ \\
\hline M00-M99 & Diseases of the musculoskeletal system & 6296 & 12623 & $1.06(1.03$ to 1.09$) \ddagger$ \\
\hline M15-M19 & Arthrosis & 925 & 1881 & $1.06(0.98$ to 1.14$)$ \\
\hline M54 & Dorsalgia & 1475 & 2817 & $1.11(1.04$ to 1.18$) \ddagger$ \\
\hline N00-N99 & Diseases of the genitourinary system & 1518 & 3648 & $0.89(0.84$ to 0.95$) \ddagger$ \\
\hline N20 & Calculus of kidney and ureter & 140 & 321 & $0.93(0.76$ to 1.14$)$ \\
\hline N40 & Hyperplasia of prostate & 418 & 1032 & $0.88(0.79$ to 0.99$) \ddagger$ \\
\hline R00-R99 & Findings, not elsewhere classified & 1091 & 2297 & $1.01(0.94$ to 1.09$)$ \\
\hline V01-Y98 & External causes of morbidity & 5084 & 10055 & $1.07(1.03$ to 1.11$) \ddagger$ \\
\hline V01-V99 & Transport accidents & 171 & 423 & $0.85(0.71$ to 1.02$)$ \\
\hline W00-W19 & Falls & 2010 & 3817 & $1.11(1.06$ to 1.18$) \ddagger$ \\
\hline W20-W49 & Exposure to mechanical forces & 1864 & 3799 & 1.03 (0.98 to 1.09$)$ \\
\hline X31 & Excessive cold & 26 & 32 & 1.74 (1.04 to 2.92$) \ddagger$ \\
\hline
\end{tabular}


Table 2 Continued

\begin{tabular}{|c|c|c|c|c|}
\hline \multirow[b]{2}{*}{ ICD-10 } & \multirow[b]{2}{*}{ Diagnosis/external cause of morbidity } & \multicolumn{2}{|c|}{ No. of cases } & \multirow[b]{2}{*}{$\mathbf{R R}(95 \% \mathrm{Cl})$} \\
\hline & & $\begin{array}{l}\text { Exposed } \\
\text { cohort }\end{array}$ & $\begin{array}{l}\text { Unexposed } \\
\text { cohort }\end{array}$ & \\
\hline X40-X49 & Accidental poisoning & 34 & 69 & 1.05 (0.69 to 1.58$)$ \\
\hline X60-X84 & Intentional self-harm & 53 & 76 & 1.47 (1.04 to 2.09$) \ddagger$ \\
\hline Z00-Z99 & Contact with health services & 4135 & 8862 & 0.99 (0.96 to 1.03$)$ \\
\hline ZO3 & $\begin{array}{l}\text { Medical observation for suspected } \\
\text { disease }\end{array}$ & 389 & 788 & 1.06 (0.94 to 1.19$)$ \\
\hline $\begin{array}{l}\text { F10, G31.2, I42.6, K70, } \\
\text { K86.0, X45, X65, Y15 }\end{array}$ & $\begin{array}{l}\text { Selected alcohol-induced diagnoses and } \\
\text { external causes of morbidity }\end{array}$ & 528 & 896 & 1.25 (1.12 to 1.39$) \ddagger$ \\
\hline
\end{tabular}

\section{DISCUSSION}

The first non-cancer morbidity analysis of the Estonian cohort of Chernobyl cleanup workers revealed elevated morbidity for diseases of the nervous system, digestive system, musculoskeletal system, ischaemic heart disease and for external causes. The most salient excess risk was

Table 3 Adjusted morbidity RR ${ }^{\star}$ with $95 \%$ Cls by exposure for selected diagnoses and external causes of morbidity in the Estonian cohort of Chernobyl cleanup workers (3506 persons), 2004-2012

\begin{tabular}{|c|c|c|c|c|c|}
\hline ICD-10 & $\begin{array}{l}\text { Diagnosis/external } \\
\text { cause of morbidity }\end{array}$ & $\begin{array}{l}\text { Year of arrival } \\
1986 t\end{array}$ & $\begin{array}{l}\text { Duration of stay } \\
\geq 92 \text { days } \dagger\end{array}$ & $\begin{array}{l}\text { Ethnicity } \\
\text { Non-Estonian† }\end{array}$ & $\begin{array}{l}\text { Education } \\
\text { Basic or less }\end{array}$ \\
\hline D00-D48 & $\begin{array}{l}\text { In situ and benign } \\
\text { neoplasms }\end{array}$ & 1.15 (0.95 to 1.39$)$ & 0.77 (0.64 to 0.92$) \ddagger$ & 1.09 (0.91 to 1.30$)$ & $0.76(0.61$ to 0.96$) \ddagger$ \\
\hline E00-E07 & $\begin{array}{l}\text { Diseases of thyroid } \\
\text { gland }\end{array}$ & 0.94 (0.68 to 1.31$)$ & $1.00(0.73$ to 1.38$)$ & 0.85 (0.62 to 1.17$)$ & 0.82 (0.55 to 1.22$)$ \\
\hline F00-F99 & Mental disorders & $1.08(0.96$ to 1.21$)$ & 0.85 (0.76 to 0.95$) \ddagger$ & $0.82(0.74$ to 0.92$) \ddagger$ & $1.11(0.97$ to 1.27$)$ \\
\hline $\begin{array}{l}\text { F32-F33, } \\
\text { F43 }\end{array}$ & $\begin{array}{l}\text { Depressive disorders } \\
\text { and stress reactions }\end{array}$ & $1.27(1.00$ to 1.62$)$ & $0.72(0.58$ to 0.90$) \ddagger$ & 0.53 (0.41 to 0.67$) \ddagger$ & 0.88 (0.66 to 1.17$)$ \\
\hline G00-G99 & $\begin{array}{l}\text { Diseases of the } \\
\text { nervous system }\end{array}$ & $1.01(0.90$ to 1.13$)$ & 0.93 (0.83 to 1.04$)$ & 0.97 (0.87 to 1.09$)$ & $1.20(1.05$ to 1.37$) \ddagger$ \\
\hline G43-G44 & $\begin{array}{l}\text { Migraine and other } \\
\text { headache }\end{array}$ & 1.69 (1.10 to 2.60$) \ddagger$ & $0.79(0.55$ to 1.14$)$ & 1.48 (1.03 to 2.12$) \ddagger$ & $0.97(0.59$ to 1.58$)$ \\
\hline $\begin{array}{l}\mathrm{H} 25-\mathrm{H} 26, \\
\mathrm{H} 28\end{array}$ & Cataract & 1.07 (0.77 to 1.49$)$ & 1.05 (0.76 to 1.45$)$ & 1.29 (0.93 to 1.77$)$ & 0.93 (0.65 to 1.33$)$ \\
\hline $\mathrm{H} 40, \mathrm{H} 42$ & Glaucoma & 1.26 (0.83 to 1.89$)$ & $0.78(0.52$ to 1.15$)$ & 1.20 (0.81 to 1.78$)$ & $0.80(0.51$ to 1.27$)$ \\
\hline$|10-| 15$ & Hypertensive diseases & 1.03 (0.94 to 1.14$)$ & $0.92(0.84$ to 1.01$)$ & 1.07 (0.98 to 1.17$)$ & $0.99(0.88$ to 1.11$)$ \\
\hline $120-125$ & $\begin{array}{l}\text { Ischaemic heart } \\
\text { disease }\end{array}$ & $1.15(0.99$ to 1.34$)$ & $0.81(0.70$ to 0.94$) \ddagger$ & $1.12(0.97$ to 1.30$)$ & $1.10(0.93$ to 1.30$)$ \\
\hline 121 & $\begin{array}{l}\text { Acute myocardial } \\
\text { infarction }\end{array}$ & $1.11(0.74$ to 1.68$)$ & 0.94 (0.63 to 1.39$)$ & 1.53 (1.03 to 2.26$) \ddagger$ & 1.17 (0.74 to 1.83$)$ \\
\hline $160-169$ & $\begin{array}{l}\text { Cerebrovascular } \\
\text { diseases }\end{array}$ & $1.11(0.86$ to 1.42$)$ & 1.03 (0.81 to 1.42$)$ & 1.65 (1.30 to 2.11$) \ddagger$ & $1.61(1.25$ to 2.08$) \ddagger$ \\
\hline K70-K77 & Diseases of liver & $1.13(0.82$ to 1.54$)$ & $1.13(0.84$ to 1.51$)$ & $1.42(1.07$ to 1.90$) \ddagger$ & $1.12(0.79$ to 1.58$)$ \\
\hline N20 & $\begin{array}{l}\text { Calculus of kidney and } \\
\text { ureter }\end{array}$ & $1.08(0.74$ to 1.57$)$ & $0.88(0.62$ to 1.26$)$ & 1.99 (1.39 to 2.85$) \ddagger$ & $0.73(0.45$ to 1.19$)$ \\
\hline X60-X84 & Intentional self-harm & 1.27 (0.68 to 2.36$)$ & 0.77 (0.43 to 1.37$)$ & 1.43 (0.82 to 2.52$)$ & $2.73(1.48$ to 5.05$) \ddagger$ \\
\hline $\begin{array}{l}\text { F10, G31.2, } \\
\text { I42.6, K70, } \\
\text { K86.0, X45, } \\
\text { X65, Y15 }\end{array}$ & $\begin{array}{l}\text { Selected } \\
\text { alcohol-induced } \\
\text { diagnoses and external } \\
\text { causes of morbidity }\end{array}$ & $0.92(0.76$ to 1.11$)$ & $0.98(0.82$ to 1.17$)$ & $1.37(1.15$ to 1.63$) \ddagger$ & $1.76(1.44$ to 2.15$) \ddagger$ \\
\hline
\end{tabular}


observed for thyroid diseases, and as expected, for intentional self-harm and selected alcohol-induced diagnoses.

\section{Limitations}

First, this study was limited to morbidity cases between 2004 and 2012. We had no information about morbidity prior to this time period. Thus, it was not possible to specify incident cases or assess early effects of exposure.

Second, among the given diseases there could be tentative and preliminary diagnoses unconfirmed afterwards. We are aware of the possibility of diagnostic errors, upcoding and unbundling of codes associated with the use of a reimbursement-administrative database, originally created not for research purposes, but proved to be an important source for medical studies in Estonia. ${ }^{24-26}$ A small number of cases might have been diagnosed by commercial healthcare providers and not reported to the EHIF. However, because of universal health insurance, these limitations would be expected to affect the exposed and unexposed cohorts in a similar fashion. This kind of non-differential misclassification of disease or of disease status probably either does not bias the RR or biases it towards the null. The same may be said in a hypothetical situation when the validity of diagnoses in the EHIF will be almost perfect. In the last case as the most important, the number and heterogeneity of diagnostic entries would be reduced and the accuracy of measurements improved.

Third, the documented radiation doses are not entirely accurate, and there could be incorrect readings in both directions as discussed elsewhere. ${ }^{2}{ }^{19}$ Although no correlation was observed between individual doses from military passports (lists) and the biodosimetry estimates for the subcohort of cleanup workers, it is estimated that the cohort was exposed to low-dose radiation around $0.1 \mathrm{~Gy}$ on average. ${ }^{22} 27 \mathrm{~A}$ similar dose level was reported for Latvian and Lithuanian Chernobyl cleanup workers. ${ }^{28}$ Thus, we used year of arrival and duration of stay as proxy variables for radiation exposure.

Fourth, the small size of the cohort has reduced the power of analysis. In addition, because of multiple comparisons, it is possible that some statistically significant findings could be due to chance. Given these limitations, our conclusions are duly tempered.

\section{Possible radiation effects?}

Thyroid diseases have been under close surveillance after the Chernobyl accident since radioiodine (mainly ${ }^{131}$ I with a half-life of 8 days) released during the explosion is concentrated in the thyroid gland. Ron and Brenner $^{29}$ summarised the evidence of benign thyroid diseases after radiation exposure. They concluded that associations have been weak and elevated risk occurred mainly in participants with high doses, exposed at young ages and in women. Keeping in mind that the cohort of cleanup workers includes only adult men who were exposed to low doses, we cannot attribute the thyroid findings to radiation. This interpretation is supported by the lack of excess among the early entrants or participants with the highest documented radiation doses. At the same time, we cannot exclude the possibility that a higher RR among the cleanup workers is caused by close medical attention sought by them. During thyroid screening among the Estonian cleanup workers in 1995, no clear correlation was found between the prevalence of thyroid nodules and the year of arrival or recorded radiation dose. $^{30}$

High radiation doses increase the risk of circulatory diseases, but less is known about the effect of low or moderate doses $(<0.5 \mathrm{~Gy})$. Difficulty in estimating doseresponse at low dose levels is due to paucity of large cohorts with high-quality data on doses and confounders. ${ }^{10}{ }^{31}$ As the Estonian cohort of cleanup workers is small and with low average radiation dose, we cannot attribute the small increase in ischaemic heart disease morbidity seen in the cohort to biological effects of radiation exposure. This conclusion is also supported by the mortality analyses, where no excess deaths from circulatory diseases were found. ${ }^{2}$

An increased risk of cataract, observed in atomic-bomb survivors ${ }^{7}$ and Ukrainian cleanup workers, ${ }^{32}$ did not emerge in the Estonian cohort. An observed statistically significant deficit of cataract cases may be an occasional finding without any epidemiological relevance. Although cataract has been conventionally regarded as a late deterministic effect of radiation with a threshold dose of $0.5 \mathrm{~Gy}$, recent studies have suggested a need to lower this dose limit and reconsider the threshold model. ${ }^{31}{ }^{33}$ Nevertheless, it is unlikely that radiation-related cataracts will be detectable among the Estonian cleanup workers in the future, given the low-dose level.

\section{Mental and neurological disorders}

Natural or man-made disasters can inflict psychological consequences on the affected populations. Radiation events evoke images of the bombings of Hiroshima and Nagasaki, and mental health effects such as post-traumatic stress, depression, anxiety and somatisation can be long lasting. ${ }^{34}$ After the Chernobyl accident, the mental health of the local population and cleanup workers was considered to be the main public health concern. ${ }^{1}{ }^{14}$ Cleanup workers were exposed to radiation, lack of protective gear and poor living conditions, sometimes doing meaningless jobs and drinking large amounts of alcohol (mainly homedistilled). ${ }^{19} 35$ Misleading or no information about the possible long-term health effects generated rumours and misapprehensions and radiation fears were exaggerated. ${ }^{36} 37$ The situation bred profound mistrust of all authorities. One of the most difficult lessons from Chernobyl has been to gain the public's trust and to deliver scientific information about radiation risks, as there exists an insuperable gap between the experts' and public's perceptions about radiation. $^{38-40}$

Until now, the persistently elevated suicide risk in the Estonian cohort has been the definitive indication of psychological impairment as a result of working as a 
Chernobyl cleanup worker. ${ }^{2}$ However, current morbidity analyses showed a mixed pattern of mental and neurological disorders. Based on the results from a study of Ukrainian cleanup workers, ${ }^{15}$ we expected higher rates of depression, anxiety, post-traumatic stress disorder and headaches. Yet, there was no overall increase of mental disorders as a group $(\mathrm{RR}=1.00)$, or of physiciandiagnosed depression or anxiety. During the follow-up period, the cleanup workers used healthcare services significantly less frequently for stress reactions than the unexposed cohort. No excess of severe headaches or sleep disorders was found among cleanup workers. However, depression and stress reactions and severe headaches were more frequent in the early entrants. Elevated morbidity due to intentional self-harm is also an indicator of psychological distress. This finding is consistent with the increased suicide rate in the cohort, ${ }^{2}$ which is strongly related to alcohol dependence among middle-aged men in Estonia. ${ }^{41}$

Smoking and heavy alcohol consumption are more prevalent in less educated men in Estonia. ${ }^{42} 43$ Although population-based health (behaviour) prevalence studies do not report differences in smoking and drinking habits between Estonians and non-Estonians, ${ }^{42}{ }^{43}$ mortality is higher in non-Estonians, ${ }^{44}$ particularly alcoholrelated mortality. ${ }^{45}$

Excess morbidity emerged for alcohol-induced diseases-mental disorders due to alcohol and degeneration of the nervous system due to alcohol. Morbidity from alcohol-induced diagnoses as a group was $25 \%$ higher among cleanup workers than in the unexposed cohort. Considering common alcohol abuse among men in Estonia (especially with lower educational level), ${ }^{43}$ it is not surprising that cleanup workers used alcohol to cope with stressful situations, and still do. Higher morbidity due to excessive cold is most likely attributable to homelessness and suggests that periods of homelessness were more common in cleanup workers than in men in the comparison cohort. Results of our study demonstrate that the men with Estonian ethnicity and/or higher educational level coped better with Chernobyl consequences including alcohol abuse.

Although Ukrainian cleanup workers had more mental disorders than controls, no excess of alcoholism was observed. ${ }^{15}$ This illustrates how analysis of similar cohorts with different design and risk measures can produce entirely opposite results. Very likely, mental disorders other than alcoholism were underdiagnosed in the Estonian cohort, and the prevalence of alcohol problems was underestimated in the Ukrainian cohort. It is common that people do not seek professional help for mental health problems. ${ }^{34}$ Untreated mental disorders can manifest as unexplained physical symptoms such as headache or back pain, or they are risk factors for somatic diseases (eg, thyroid diseases or diseases of the digestive system). ${ }^{46} 47$ Thus, it is important to pay attention to mental and somatic diseases of Chernobyl cleanup workers simultaneously.

\section{CONCLUSIONS}

No obvious excess morbidity consistent with biological effects of radiation was seen in the exposed cohort, with the possible exception of benign thyroid diseases. Increased alcohol-induced morbidity reflects alcohol abuse, and could underlie some of the higher morbidity rates. Mental disorders in the exposed cohort were probably under-reported. The future challenge will be to study mental and physical comorbidities in the Chernobyl cleanup workers cohort.

Acknowledgements The authors thank Triin Habicht and Elin Raaper from the Estonian Health Insurance Fund for data linkages.

Contributors KR and MR designed the study. KR performed the statistical analyses and drafted the manuscript. EJB, TH, AA, AU and MR contributed to the interpretation of the results and revised the manuscript critically. MR supervised the whole process. All authors have seen and approved the final version of the manuscript.

Funding This stage of the study was supported financially by the Estonian Research Council (IUT5-1) and by the Estonian Ministry of Education and Research (target funding SF0180060s09).

Competing interests None.

Ethics approval The study was approved by the Tallinn Medical Ethics Committee (no. 1939, 11 February 2010) and by the Estonian Data Protection Inspectorate (no. 2.2-3/10/120r, 9 April 2010).

Provenance and peer review Not commissioned; externally peer reviewed.

Data sharing statement No additional data are available.

Open Access This is an Open Access article distributed in accordance with the Creative Commons Attribution Non Commercial (CC BY-NC 3.0) license, which permits others to distribute, remix, adapt, build upon this work noncommercially, and license their derivative works on different terms, provided the original work is properly cited and the use is non-commercial. See: http:// creativecommons.org/licenses/by-nc/3.0/

\section{REFERENCES}

1. United Nations Scientific Committee on the Effects of Atomic Radiation. Sources and effects of ionizing radiation. UNSCEAR 2008 report to the General Assembly with scientific annexes, volume II, scientific annex D: health effects due to radiation from the Chernobyl accident. New York: United Nations, 2011.

2. Rahu K, Auvinen A, Hakulinen T, et al. Chernobyl cleanup workers from Estonia: follow-up for cancer incidence and mortality. J Radiol Prot 2013;33:395-411.

3. Shimizu Y, Kodama K, Nishi N, et al. Radiation exposure and circulatory disease risk: Hiroshima and Nagasaki atomic bomb survivor data, 1950-2003. BMJ 2010;340:b5349.

4. Vrijheid M, Cardis E, Ashmore $\mathrm{P}$, et al. Mortality from diseases other than cancer following low doses of ionizing radiation: results from the 15 -Country Study of nuclear industry workers. Int J Epidemiol 2007;36:1126-35

5. Ozasa K, Shimizu Y, Suyama A, et al. Studies of the mortality of atomic bomb survivors, report 14, 1950-2003: an overview of cancer and noncancer diseases. Radiat Res 2012;177:229-43.

6. Boice JD Jr, Mumma MT, Blot WJ. Cancer incidence and mortality in populations living near uranium milling and mining operations in Grants, New Mexico, 1950-2004. Radiat Res 2010;174:624-36.

7. Yamada M, Wong FL, Fujiwara S, et al. Noncancer disease incidence in atomic bomb survivors, 1958-1998. Radiat Res 2004;161:622-32.

8. Azizova TV, Muirhead CR, Moseeva MB, et al. Cerebrovascular diseases in nuclear workers first employed at the Mayak PA in 1948-1972. Radiat Environ Biophys 2011;50:539-52.

9. Azizova TV, Muirhead CR, Moseeva MB, et al. Ischemic heart disease in nuclear workers first employed at the Mayak PA in 19481972. Health Phys 2012;103:3-14.

10. Little MP, Azizova TV, Bazyka D, et al. Systematic review and meta-analysis of circulatory disease from exposure to low-level 
ionizing radiation and estimates of potential population mortality risks. Environ Health Perspect 2012;120:1503-11.

11. Ivanov VK, Maksioutov MA, Chekin SYu, et al.

Radiation-epidemiological analysis of incidence of non-cancer diseases among the Chernobyl liquidators. Health Phys 2000;78:495-501.

12. Ivanov VK, Maksioutov MA, Chekin SY, et al. The risk of radiation-induced cerebrovascular disease in Chernobyl emergency workers. Health Phys 2006;90:199-207.

13. Preston RJ, Boice JD Jr, Brill AB, et al. Uncertanties in estimating health risks associated with exposure to ionising radiation. $J$ Radiol Prot 2013;33:573-88.

14. Balonov MI. The Chernobyl Forum: major findings and recommendations. J Environ Radioact 2007;96:6-12.

15. Loganovsky K, Havenaar JM, Tintle NL, et al. The mental health of clean-up workers 18 years after the Chernobyl accident. Psychol Med 2008;38:481-8.

16. Bromet EJ, Havenaar JM, Guey LT. A 25 year retrospective review of the psychological consequences of the Chernobyl accident. Clini Oncol (R Coll Radiol) 2011;23:297-305.

17. Rahu M, Tekkel M, Veidebaum T, et al. The Estonian study of Chernobyl cleanup workers: II. Incidence of cancer and mortality. Radiat Res 1997;147:653-7.

18. Rahu K, Rahu M, Tekkel M, et al. Suicide risk among Chernobyl cleanup workers in Estonia still increased: an updated cohort study. Ann Epidemiol 2006;16:917-19.

19. Tekkel M, Rahu M, Veidebaum T, et al. The Estonian study of Chernobyl cleanup workers: I. Design and questionnaire data. Radiat Res 1997;147:641-52.

20. Koppel A, Kahur K, Habicht T, et al. Estonia: health system review. Health Syst Transit 2008;10:1-230.

21. Clayton D, Hills M. Statistical models in epidemiology. New York Oxford University Press, 1993.

22. Bigbee $\mathrm{WL}$, Jensen $\mathrm{RH}$, Veidebaum $\mathrm{T}$, et al. Biodosimetry of Chernobyl cleanup workers from Estonia and Latvia using the glycophorin A in vivo somatic cell mutation assay. Radiat Res 1997;147:215-24.

23. Chumak VV. Physical dosimetry of Chernobyl cleanup workers Health Phys 2007:93:452-61.

24. Blöndal M, Ainla T, Marandi T, et al. Changes in treatment and mortality of acute myocardial infarction in Estonian tertiary and secondary care hospitals in 2001 and 2007. BMC Res Notes 2012;5:71

25. Müller R, Kallikorm R, Põlluste $\mathrm{K}$, et al. Compliance with treatment of rheumatoid arthritis. Rheumatol Int 2012;32:3131-5.

26. Veerus $\mathrm{P}$, Fischer K, Hakama M, et al. Results from a blind and a non-blind randomised trial run in parallel: experience from the Estonian Postmenopausal Hormone Therapy (EPHT) Trial. BMC Med Res Methodol 2012;12:44.

27. Littlefield LG, McFee AF, Salomaa SI, et al. Do recorded doses overestimate true doses received by Chernobyl cleanup workers? Results of cytogenetic analyses of Estonian workers by fluorescence in situ hybridization. Radiat Res 1998;150:237-49.
28. Rahu K, Hakulinen T, Smailyte G, et al. Site-specific cancer risk in the Baltic cohort of Chernobyl cleanup workers, 1986-2007. Eur J Cancer 2013;49:2926-33.

29. Ron E, Brenner A. Non-malignant thyroid diseases after a wide range of radiation exposures. Radiat Res 2010;174:877-88.

30. Inskip PD, Hartshorne MF, Tekkel M, et al. Thyroid nodularity and cancer among Chernobyl cleanup workers from Estonia. Radiat Res 1997; 147:225-35.

31. Little MP. A review of non-cancer effects, especially circulatory and ocular diseases. Radiat Environ Biophys 2013;52:435-49.

32. Worgul BV, Kundiyev YI, Sergiyenko NM, et al. Cataracts among Chernobyl clean-up workers: implications regarding permissible eye exposures. Radiat Res 2007;167:233-43.

33. Hammer GP, Scheidemann-Wesp U, Samkange-Zeeb F, et al. Occupational exposure to low doses of ionizing radiation and cataract development: a systematic literature review and perspectives on future studies. Radiat Environ Biophys 2013;52:303-19.

34. Bromet EJ. Lessons learned from radiation disasters. World Psychiatry 2011;10:83-4.

35. Tarlap T. Chernobyl 1986: memoirs of an Estonian cleanup worker Tallinn: IECM, 1995.

36. Rahu M. Health effects of the Chernobyl accident: fears, rumours and the truth. Eur J Cancer 2003;39:295-9.

37. Balonov MI. On protecting the inexperienced reader from Chernobyl myths. J Radiol Prot 2012;32:181-9.

38. Loewenberg S. Mikhail Balonov: understanding the legacy of Chernobyl. Lancet 2006;367:1311.

39. Thomas GA. Putting health risks from radiation exposure into context: lessons from past accidents. Ann Acad Med Singapore 2011;40:158-9.

40. Perko T. Radiation risk perception: a discrepancy between the experts and the general population. J Environ Radioact. Available online: 15 May 2013. doi: 10.1016/j.jenvrad.2013.04.005.

41. Kõlves K, Värnik A, Tooding LM, et al. The role of alcohol in suicide: a case-control psychological autopsy study. Psychol Med 2006;36:923-30.

42. Pärna K, Rahu K. Socio-economic differences in smoking. Eesti Arst 2008;88:57-62 (in Estonian).

43. Pärna K, Rahu K, Helakorpi S, et al. Alcohol consumption in Estonia and Finland: Finbalt survey 1994-2006. BMC Public Health 2010;10:261.

44. Leinsalu $M$, Vågerö $D$, Kunst $A E$. Increasing ethnic differences in mortality in Estonia after the collapse of the Soviet Union. $J$ Epidemiol Community Health 2004;58:583-9.

45. Rahu K, Pärna K, Palo E, et al. Contrasts in alcohol-related mortality in Estonia: education and ethnicity. Alcohol Alcohol 2009;44:517-22.

46. Ginzburg K, Solomon Z. Trajectories of stress reactions and somatization symptoms among war veterans: a 20 -year longitudinal study. Psychol Med 2011;41:353-62.

47. Sanna L, Stuart AL, Pasco JA, et al. Physical comorbidities in men with mood and anxiety disorders: a population-based study. BMC Med 2013;11:110. 